\title{
Diagnóstico de lesiones óseas con biopsia percutánea guiada por imágenes
}

\author{
O scar Contreras 0, Alvaro Burdiles 0.
}

\section{Diagnosis of bone lesions using image guided percutaneous biopsy}

Background: Percutaneous biopsies have a good sensitivity and specificity for the diagnosis of bone lesions. Aim: To report the experience with 270 percutaneous bone lesions biopsies guided with fluoroscopy or computed tomography. Material and Methods: Retrospective review of the medical records of 270 patients (mean age 53.4 years, range 4 to 95 years; 134 female) subjected to a percutaneous biopsy of a bone lesion, guided either by computed tomography or fluoroscopy. The final analysis included the tumor type, tumor malignancy, tumor grade and complications of the procedure. Results: One hundred seventy nine lesions were malignant and 91 benign. Of the malignant lesions, 95 were metastatic and 84 were primary. In 3 cases, the initial diagnosis was a false negative (1.1\%). Only one patient had a local hematoma after the procedure. Conclusions: Image guided percutaneous biopsy of bone lesions is a safe, effective, fast and economic procedure to obtain a pathological diagnosis of bone lesions (Rev Méd Chile 2006; 134: 1283-87).

(Key words: Biopsy, needle; Bone and bones; Neoplasms by site; Neoplasms, second primary)

Recibido el 25 de agosto, 2005. Aceptado el 18 de abril, 2006.

Sección Radiología Musculoesquelética, Departamento de Radiología, Hospital Clínico

Pontificia Universidad Católica de Chile.

L as biopsias percutáneas se han convertido en una modalidad con creciente aceptación en el estudio de lesiones musculoesqueléticas, tanto a nivel nacional como internacional. Pese a la bien documentada sensibilidad y especificidad de este método ${ }^{1-3}$, aún existe cierto grado de resistencia entre los médicos clínicos para aceptar esta técnica como la modalidad de elección inicial en el estudio de lesiones primarias óseas. Los detractores de la técnica de biopsias percutáneas afir-

Correspondencia a: Dr. Alvaro Burdiles O. Marcoleta 367, 2o piso. Teléfono: 3543886. Fax: 6336762.

E-mail: aburdiles@yahoo.com. man que no se puede obtener suficiente material para asegurar un diagnóstico preciso ${ }^{4}$.

El propósito de nuestro estudio es dar a conocer un resumen de los casos de biopsias óseas percutáneas guiadas por imágenes realizadas en nuestro Servicio de Radiología, con los resultados correspondientes.

\section{MATERIAL Y MÉTODO}

Estudiamos retrospectivamente los registros de 270 pacientes en quienes se realizó biopsia percutánea guiada por imágenes. Todas las biopsias las realizó un radiólogo experimentado (O.C.). La 
decisión de realizar la biopsia fue tomada en conjunto por el médico tratante y el radiólogo, en pacientes cuyo resultado anatomopatológico alteraría el tratamiento clínico. Por ejemplo, la biopsia no se realizó en pacientes con lesiones de aspecto benigno, pero sí en aquellos pacientes en quienes se sospechaba la posibilidad de una lesión agresiva y que pudiesen necesitar tratamiento neoadyuvante.

Entre junio de 1999 y octubre de 2004 se estudiaron 270 pacientes, 134 de sexo femenino y 136 de sexo masculino, con una edad promedio de 53,4 años y un rango de edad de 4 a 95 años. $\mathrm{Si}$ consideramos solamente las biopsias realizadas a pacientes con lesiones en la columna vertebral, el total alcanza 114 pacientes, 60 de sexo femenino y 54 de sexo masculino, con una edad promedio de 62,3 años y un rango de edad de 17 a 95 años.

Las biopsias fueron evaluadas por patólogos con extensa experiencia en lesiones musculoesqueléticas. El diagnóstico anatomopatológico definitivo incluyó tipo de tumor y, en caso de ser maligno, el grado tumoral.

Todas las biopsias fueron planificadas de manera que la vía de ingreso y su dirección evitaran la contaminación intercompartimental y, por cierto, las estructuras neurovasculares.

En 251 casos, las biopsias percutáneas fueron realizadas con guía tomográfica (tomografía computada, TC) y con guía fluoroscópica en 19 casos. El uso de TC en lugar de fluoroscopia fue determinada en base a tres factores. En primer lugar, el tamaño de la lesión. Las lesiones peque- ñas fueron biopsiadas bajo TC, mientras que las lesiones grandes eran potenciales candidatas a ser biopsiadas bajo fluoroscopia. En segundo lugar, se consideró el sitio de incisión en la cirugía de resección y la proximidad a estructuras neurovasculares. Si existía la posibilidad de contaminar potencialmente el paquete neurovascular, se prefería la guía tomográfica. Finalmente, se consideró la disponibilidad de las salas de TC o de fluoroscopia (angiografía), considerando que las salas de TC suelen contar con mayor disponibilidad (Figuras 1,2 y 3 ).

La decisión de utilizar fluoroscopia para la biopsia de lesiones vertebrales, se basó en la exitosa experiencia de aproximación transpedicular para las vertebroplastias percutáneas realizadas en nuestro servicio (más de 50 casos).

Recomendamos realizar sedación endovenosa en aquellos pacientes en quienes sea necesario realizar múltiples muestras o utilizar agujas de mayor calibre. Así se evita el dolor del paciente, lo que puede apresurar inadecuadamente el término del procedimiento.

Los pacientes fueron sedados con midazolam ev (0,5-4 mg) y fentanyl (25-20 $\mu \mathrm{g})$, con monitorización continua de frecuencia cardíaca, presión arterial y oximetría de pulso.

El procedimiento se realizó sin la presencia de un citopatólogo en la sala de examen. Se realizaron estudios con biopsia core en todos los pacientes, con un promedio de 2 muestras por cada paciente. Basado en la composición interna de la lesión, la técnica de la biopsia fue adaptada para el tipo específico de lesión.

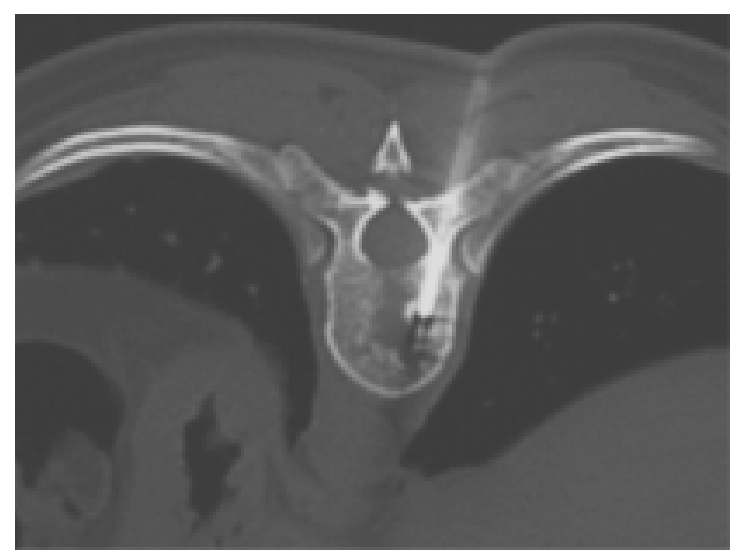

FiguRA 1. Imagen de tomografía computada, en corte axial, que demuestra la presencia de una lesión ósea de estructura interna heterogénea en un cuerpo vertebral dorsal bajo. Es visible la aguja de biopsia ósea que ingresa por vía transpedicular izquierda hasta alcanzar la lesión en el cuerpo vertebral. El estudio histológico demostró la presencia de metástasis de cáncer de mama. 


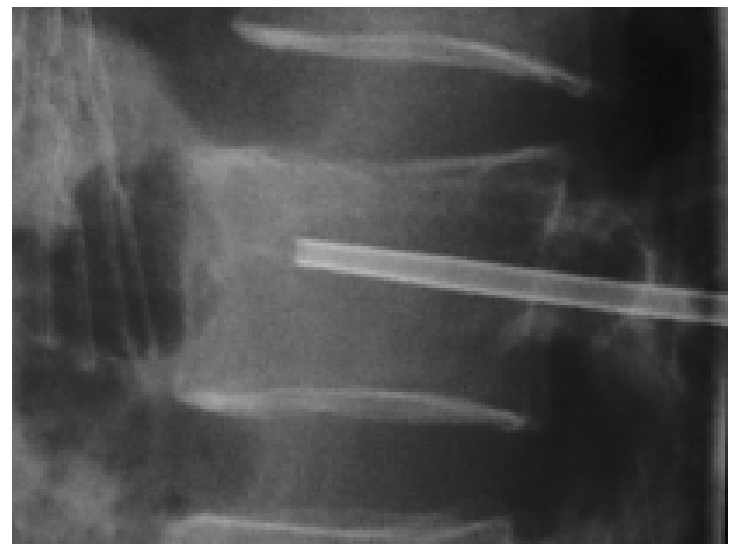

FIGURA 3. Imagen de tomografía computada, en corte axial, que demuestra la presencia de una lesión ósea femoral, con extensas calcificaciones que corresponden a una matriz osteoide. Es visible la aguja de biopsia ósea que ingresa por vía percutánea hasta alcanzar la lesión. El estudio histológico demostró la presencia de un osteosarcoma.

El análisis final de las biopsias óseas incluyó la presencia de tumor, el tipo de tumor, presencia de malignidad, grado tumoral y complicaciones de la biopsia.

El seguimiento de los pacientes estuvo a cargo de los departamentos de oncología y de ortopedia y traumatología de nuestra institución. Se comparó el resultado de la biopsia percutánea con el resultado quirúrgico (en caso de haberse realizado cirugía) o bien con el seguimiento clínico.
FiguRa 2. Proyección radiográfica lateral de cuerpo vertebral lumbar, durante biopsia percutánea guiada por fluoroscopia. Se observa la aguja de biopsia ósea que alcanza la lesión en el cuerpo vertebral por vía transpedicular. El estudio histológico demostró la presencia de mieloma múltiple.

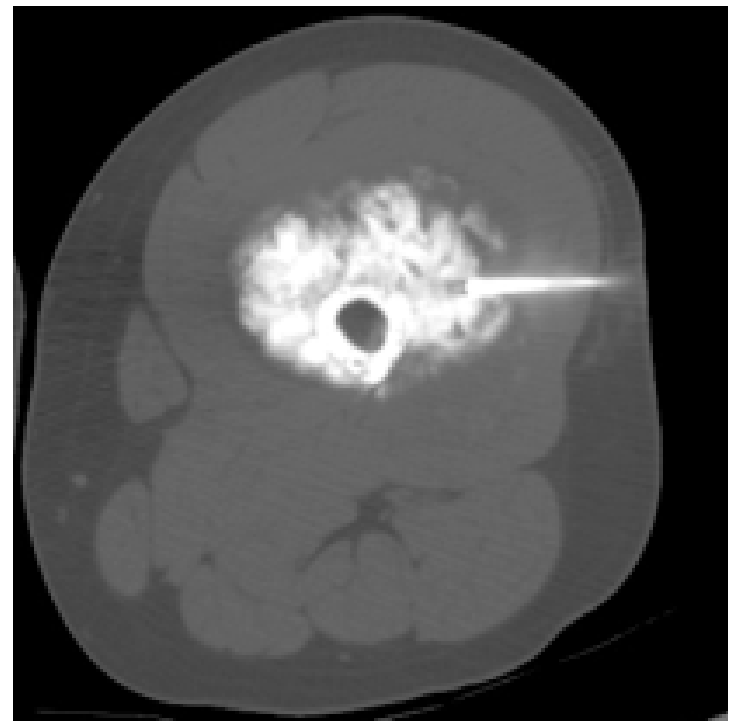

\section{Resultados}

El 20,3\% de las lesiones biopsiadas corresponden a 4 diagnósticos: metástasis de cáncer de mama (18 casos), metástasis de cáncer de pulmón (13), encondroma (13) y mieloma múltiple (11) (Tabla 1).

En relación a las complicaciones, no se observó ningún caso de daño vascular o nervioso. La única complicación observada fue un pequeño hematoma que fue tratado en forma conservadora. 
Tabla 1.

\begin{tabular}{|c|c|c|c|c|}
\hline Resultados & & & & \\
\hline No tumorales & 91 & & & \\
\hline & & Necrosis & & 4 \\
\hline & & Infección & Ostomielitis & 10 \\
\hline & & & Ostomielitis tuberculosa & 3 \\
\hline Metástasis & 95 & Linfoma & Hodgkin & 5 \\
\hline & & Pulmón & & 13 \\
\hline & & Mama & & 18 \\
\hline & & Indiferen & lo o poco diferenciado & 15 \\
\hline & & Otros & & 44 \\
\hline Mieloma & 17 & Mieloma & ltiple & 11 \\
\hline & & Mieloma & lerosante & 2 \\
\hline & & Plasmaci & & 4 \\
\hline Primario & 67 & Encondr & & 13 \\
\hline & & Tumor d & lulas gigantes & 7 \\
\hline & & Quiste ó & simple & 7 \\
\hline & & Osteosar & & 7 \\
\hline & & Otros & & 33 \\
\hline
\end{tabular}

En 3 casos el diagnóstico inicial resultó ser falso negativo (1,1\% de los casos), sin embargo, un segundo procedimiento de biopsia permitió obtener muestra suficiente que confirmó en forma definitiva el diagnóstico histológico.

\section{DISCUSIÓN}

La técnica de biopsia percutánea utilizando tomografía computada, fluoroscopia, ultrasonografía, e incluso resonancia magnética como guía, ha reemplazado virtualmente el requerimiento de biopsia quirúrgica abierta, en tórax, abdomen, pelvis, columna y extremidades. La amplia aceptación de estas técnicas ha sido lenta y progresivamente incorporada por los médicos clínicos ${ }^{4}$.

Los resultados de este estudio muestran que esta técnica, realizada en situaciones cuidadosamente estudiadas por el médico radiólogo, trabajando en conjunto con el medico clínico y el anatomopatólogo, puede ser extremadamente efectiva y precisa.

Como se ha demostrado en varios estudios previos, la relación costo-efectividad de la biopsia percutánea guiada por imágenes, comparada con la de la biopsia abierta, es tres a siete veces superior ${ }^{1}$. Otras ventajas adicionales de la biopsia percutánea incluyen la posibilidad de tomar muestras de distintos cuadrantes de la lesión, una menor tasa de complicaciones, permite una mejor planificación del manejo clínico, la capacidad de comenzar rápidamente con terapia adyuvante preoperatoria y así diminuir la masa tumoral en la cirugía. Con un diagnóstico patológico definitivo, se puede comenzar una terapia neoadyuvante (quimioterapia 0 radioterapia) el día siguiente a la biopsia percutánea. En cambio, después de una biopsia quirúrgica existe un retraso de días a semanas, necesarias para que la herida cicatrice y se prevengan las infecciones y el sangrado en el sitio operatorio4.

Si se planifica una cirugía de resección de la lesión, se deben atender estrictamente las recomendaciones del cirujano ortopédico, para evitar la contaminación de compartimentos o lesiones de estructuras neurovasculares ${ }^{1}$. La anatomía de los compartimentos a biopsiar debe ser conocida en detalle por el radiólogo que realiza el procedimiento y consultar al cirujano ortopédico respecto de la planificación de la cirugía. 
La tasa de complicaciones en nuestro estudio fue extremadamente baja, lo que obedece a una planificación cuidadosa, evitando estructuras neurovasculares. Dado que la mayoría de los casos se realizaron bajo guía tomográfica, el trayecto neurovascular fue definido cuidadosamente. En los casos en que la lesión es grande y no existe un paquete neurovascular en el trayecto de la biopsia, se puede utilizar la guía fluoroscópica.

La biopsia abierta puede resultar en retardo en la cicatrización e infección ${ }^{5}$. En contraste, la biopsia percutánea no requiere tiempo destinado a la cicatrización de la herida y ofrece un riesgo sustancialmente menor de infección. A modo de comparación, las biopsias abiertas pueden incluir complicaciones anestésicas, hematomas en el lecho operatorio, infecciones, así como fracturas patológicas, si el hueso es interrumpido significativamente ${ }^{2}$.

\section{REFERENCIAS}

1. Ruhs S, EL-Khoury G, ChrischiLes E. A cost minimization approach to the diagnosis of skeletal neoplasms. Skeletal Radiol 1996; 25: 449-54.

2. Destouet JM, Monsees B. Percutaneous bone biopsy: technique and results. Appl Radiol 1985; MarApr: 19-27.

3. Fraser-Hill MA, Renfrew DL, Hilserath PE. Pencutaneous needle biopsy of musculoskeletal lesions.
Un enfoque multidisciplinario minimiza la realización de biopsias inapropiadas y permite un mejor rendimiento diagnóstico de cada procedimiento. Esta técnica de biopsia percutánea debe ser considerada como una primera línea de enfrentamiento en lesiones óseas en la cuales la biopsia modificará el manejo clínico.

En conclusión la técnica de biopsia ósea percutánea guiada por imágenes, sean de lesiones primarias o secundarias, permite un alto grado de precisión en el diagnóstico de una manera efectiva, rápida, segura y económica. Esto determinará a su vez una disminución en el número de lesiones que van a biopsia quirúrgica.

Un adecuado estudio del tipo de composición interna de la lesión puede ser determinante en la planificación del procedimiento.

Effective accuracy and diagnostic utility. AJR Am J Roentgenol 1992; 158: 809-12.

4. Jeinek J, Murphey M, WeikerJ, Henshaw R, Kransdorf M, SHMOOKIER B ET AL. Diagnosis of primary bone tumors with image-guided percutaneous biopsy: expenence with 110 tumors. Radiology 2002; 223: 731-7.

5. Mankin HJ, Lange TA, Spanier SS. The hazards of biopsy in patients with malignant primary bone and soft-tissue tumors. J Bone Joint Surg Am 1982; 64: 1121-7. 